East African Medical Journal Vol. 81 No. 2 February 2004

INDUCED ABORTION AMONG WOMEN ATTENDING ANTENATAL CLINICS IN YAOUNDE, CAMEROON

J. J. Mosoko, National AIDS Control Committee, Ministry of Public Health, Box 1459, Yaounde, Cameroon, T. Delvaux, MD, MPH, STD/HIV Research and Intervention Unit, Institute of Tropical Medicine, 155, Nationalestraat, 2000 Antwerp, Belgium, J. R. Glynn, London School of Hygiene and Tropical Medicine, Keppel Street, WClE 7HT London, UK, L. Zekeng, National AIDS Control Committee, Ministry of Public Health, Box 1459, Yaounde, Cameroon, I. Macauley, National AIDS Control Committee, Ministry of Public Health, Box 1459, Yaounde, Cameroon and A. Buve, STD/HIV Research and Intervention Unit, Institute of Tropical Medicine, 155, Nationalestraat, 2000 Antwerp, Belgium

Request for reprints to: Dr. T. Delvaux, STD/HIV Research and Intervention Unit, Institute of Tropical Medicine, 155 Nationalestraat, 2000 Antwerp, Belgium

\title{
INDUCED ABORTION AMONG WOMEN ATTENDING ANTENATAL CLINICS IN YAOUNDE, CAMEROON
}

\author{
J. J. MOSOKO, T. DELVAUX, J. R. GLYNN, L. ZEKENG, I. MACAULEY and A. BUVE
}

\begin{abstract}
Objectives: Unsafe abortion is a public health concern because of its impact on maternal morbidity and mortality. The objective of this study was to document on induced abortion in Yaounde, Cameroon.

Design: Cross-sectional study.

Setting: Six antenatal clinics in Yaounde, Cameroon.

Methods: Women attending antenatal clinics between October and December 1998 were included in the study and interviewed. Nulliparous were women with no previous delivery and multiparous were defined as women who had at least one previous delivery. Results: Out of the 1532 women, five hundred seventy-two were nulliparous and 960 were multiparous. Of the nulliparous women $17 \%$ reported a previous abortion ever; this proportion exceeded $35 \%$ in those over 24 years. For multiparous women, the proportion who reported an abortion (between the last birth and present pregnancy) was $22 \%$. In multivariate analysis on the group of nulliparous women, older age, having used modern contraception and having spent more than two years in the city were significantly associated with induced abortion. In the multiparous group, older age, having a full time job and antenatal clinic were significantly associated with induced abortion.

Conclusions: This study shows that induced abortion is a common practice in urban Cameroon. Because of restrictive laws, a substantial proportion of these abortions are likely to be unsafe, with the risk of associated complications. There is a need for expanded comprehensive sexual and reproductive health services.
\end{abstract}

\section{INTRODUCTION}

Out of the 40-60 million abortions that are performed each year worldwide, an estimated 20 million are considered unsafe. Of these unsafe abortions $95 \%$ occur in developing countries(1). According to the World Health Organisation about 80,000 women die each year as a consequence of unsafe abortion and over $95 \%$ of these deaths occur in low income countries. The existence of restrictive and punitive laws in relation to abortion found in most sub-Saharan African countries(2,3) is associated with high rates of unsafe abortions(1). Unsafe abortions have a significant impact on maternal mortality and morbidity(4-11). Data on unsafe abortion in developing countries however are often limited and of questionable validity since women may be unwilling to admit to illegal abortion especially in acute situations. The degree of under reporting of abortion depends on the degree to which the laws are enforced and on the social and cultural attitudes towards abortion. In Cameroon, abortion is subject to legislation and is only authorised if the physical health of the woman is in danger(2,3). A baseline reproductive health survey conducted in 1996 revealed that $9 \%$ of women aged 15 to 17 years and $20 \%$ of women aged 18 to 22 years had had an abortion(12). In another study among child bearing women aged 12 to 19 years, $20 \%$ of respondents had used an abortion method and at least $14 \%$ had had at least one abortion(13). Young women in Cameroon are especially at risk of unsafe abortion and sexually transmitted infections (STIs). Girls reach maturity without knowledge about female physiology or sexuality(14). Their main source of information on STIs and contraception are the mass media and friends, which are not always reliable(15). Unwanted pregnancies which may lead to unsafe abortion, occur as a result of unprotected sex which also exposes them to STIs and HIV infection.

The objective of our study was to document about abortion in Cameroon, using data collected during antenatal care. We sought to assess the proportion of women attending antenatal care who reported a previous abortion and to identify factors associated with induced abortion. Based on the results of this study, interventions to strengthen reproductive health services in Cameroon are discussed. 


\section{MATERIALS AND METHODS}

Following a population based study on HIV infection and risk factors for it in the general population of Yaounde, a study was conducted among women attending antenatal clinics (ANCs) to assess the causes and extent of bias in estimates of HIV prevalence that are based on surveillance of ANCs attendees(16). There are ten major ANCs in Yaounde where onsite screening for syphilis is carried out. Out of these, six clinics that were selected were considered representative of different parts of town. All women visiting these ANCs for the first time in the present pregnancy between $15^{\text {th }}$ October and 22nd December 1998 were eligible for inclusion. Procedures followed routine sentinel surveillance as far as possible but with a longer interview. Women who consented to participate in the study were first interviewed about their socio-demographic characteristics and their reproductive history. Blood was taken for syphilis serology and treatment was provided if necessary. HIV testing was conducted later, anonymously. Detailed methods have been described elsewhere(17).

A total of 1532 pregnant women were included in the study of whom 572 were nulliparous (with no previous delivery) and 960 were multiparous (meaning that they had had at least one previous delivery). One of the aims of the original study was to investigate the influence of HIV on fertility, so information was collected on other factors known to influence fertility including abortion and miscarriage. In order to avoid confusion between induced and spontaneous abortion, separate questions were asked about abortion and miscarriages. Nulliparous women were asked whether they had ever had an abortion, so previous abortion for them meant any history of induced abortion, before the present pregnancy multiparous women were asked about any abortion between the last birth and the present pregnancy so in this case previous abortion meant any history of induced abortion between the last birth and the present pregnancy.

Data management and analysis: All analyses were done separately for nulliparous women and multiparous women, because of the different definitions of previous abortions as outlined above. First the proportions of nulliparous and of multiparous women who reported a history of induced abortion were calculated. A variety of factors were explored for their association with a history of induced abortion. The variables age, reported age at first sexual intercourse and age at first marriage were categorised into groups of public health significance. Factors that were found to be significantly associated with a history of induced abortion at the $5 \%$ level in analysis were entered in a logistic regression model. As appropriate, age groups and education levels were entered as dichotomous variables in the final logistic regression to alleviate the model. Duration of sexual activity was very strongly correlated with age and age at first marriage restricted the analysis to married women; therefore these two variables were not included in the final models although they were examined.

Ethical Considerations. Ethical approval for the study was obtained from the National Ethical Committee in Cameroon and the Ethical Committees of the Institute of Tropical Medicine and the London School of Hygiene and Tropical Medicine.
RESULTS

General characteristics of study population: Of the 1532 pregnant women that were enrolled in this study, $572(37 \%)$ were nulliparous and 960 (63\%) were multiparous. The general characteristics of the study population are summarised in Table 1. Nulliparous women were younger than multiparous women. The average age of the nulliparous women was 20.7 years and $84 \%$ were between 15 and 24 years. The average age of the multiparous women was 26.7 years and $67 \%$ were between 20 and 29 years. Nulliparous women had a higher level of education than multiparous women (75\% secondary education or higher vs $65 \%$ ) and were less often housewives ( $40 \%$ vs $60 \%$ ). The distribution of religion and ethnic group was similar among nulliparous women and multiparous women. Of the nulliparous women $72 \%$ had lived in Yaounde for at least two years whereas this was $90 \%$ for the multiparous women. Fiftysix percent of nulliparous women and $89 \%$ of multiparous women were married. Age at first marriage and the proportion of women who had their first sexual experience before age 16 were similar in both groups of women. As could be expected multiparous women were sexually active for a longer time than nulliparous women: $85 \%$ were sexually active for five years or more vs $34 \%$ for the nulliparous women. The majority $(65 \%)$ of nulliparous women had not used any contraceptive method before the current pregnancy and only $18 \%$ had used a modern method, including condoms. Among the multiparous women, 59\% had not used any contraceptive method between the last birth and the current pregnancy and 25\% had used a modern method, including condoms. Eightysix percent of multiparous women had given birth to fewer than five children. Similar proportions of nulliparous women and of multiparous women reported previous miscarriage, $7.2 \%$ and $7.9 \%$ respectively. The HIV prevalence among all women was $5.6 \%$. Multiparous women had a slightly higher HIV prevalence $(5.8 \%)$ than nulliparous women $(5.1 \%)$.

Nulliparous women: Seventeen percent of nulliparous women reported one or more induced abortions (Table 2 ). The majority of these women had one abortion but $5.3 \%$ reported two or more abortions. Of the women less than 20 years old, $9 \%$ reported a history of abortion; this proportion exceeded $35 \%$ in those over 24 years (Figure 1). In univariate analysis higher level of education, being a student and having lived in Yaounde for at least two years were statistically significantly associated with previous induced abortion. Also women who had used a contraceptive method and women who got married at a later age and had their first sexual intercourse at a later age were more likely to report previous abortion. Muslim women and women who did not attend Clinic A were less likely to report a history of abortion. In multivariate analysis only older age, longer residence in Yaounde and ever use of modern contraceptives were statistically significant factors associated with induced abortion. 
Table 1

Characteristics of women attending antenatal clinics in Yaounde, Cameroon

\begin{tabular}{|c|c|c|c|c|}
\hline \multirow[t]{2}{*}{ Characteristic } & \multicolumn{2}{|c|}{ Nulliparous women $(\mathrm{N}=572)$} & \multicolumn{2}{|c|}{ Multiparous women $(\mathrm{N}=960)$} \\
\hline & No. & $\%$ & No. & $\%$ \\
\hline Age group $<20$ & 256 & 44.8 & 53 & 5.5 \\
\hline $20-24$ & 225 & 39.9 & 305 & 31.8 \\
\hline $25-29$ & 72 & 12.6 & 340 & 35.4 \\
\hline $30-44$ & 18 & 3.2 & 262 & 27.3 \\
\hline \multicolumn{5}{|l|}{ Education } \\
\hline Never/primary & 142 & 24.8 & 334 & 34.8 \\
\hline Secondary & 376 & 65.9 & 566 & 59.0 \\
\hline Higher & 53 & 9.3 & 60 & 6.3 \\
\hline \multicolumn{5}{|c|}{ Current employment of woman } \\
\hline Full time & 64 & 11.2 & 97 & 10.1 \\
\hline Housewife & 228 & 40.0 & 575 & 59.9 \\
\hline Student & 147 & 25.7 & 63 & 6.6 \\
\hline Other* & 132 & 23.1 & 225 & 23.4 \\
\hline \multicolumn{5}{|l|}{ Religion } \\
\hline Protestant & 159 & 27.8 & 238 & 24.8 \\
\hline Catholic & 357 & 62.4 & 601 & 62.6 \\
\hline Muslim /Other & 56 & 9.8 & 121 & 12.6 \\
\hline \multicolumn{5}{|l|}{ Ethnicity } \\
\hline Beti/Fan & 172 & 30.1 & 303 & 31.6 \\
\hline Bamileke & 196 & 34.3 & 373 & 38.8 \\
\hline Other & 203 & 35.6 & 284 & 29.6 \\
\hline \multicolumn{5}{|l|}{ Time spent in city } \\
\hline$<2$ years & 158 & 27.6 & 96 & 10.0 \\
\hline$\geq 2$ years & 414 & 72.4 & 864 & 90.0 \\
\hline \multicolumn{5}{|l|}{ Marital status } \\
\hline Never married & 222 & 38.8 & 65 & 6.8 \\
\hline Married & 320 & 55.9 & 850 & 88.5 \\
\hline Past marriage & 30 & 5.2 & 45 & 4.7 \\
\hline \multicolumn{5}{|l|}{ Age at $1^{\text {st }}$ marriage** } \\
\hline$<17$ & 75 & 22.4 & 166 & 19.0 \\
\hline $17-20$ & 175 & 52.2 & 431 & 49.1 \\
\hline$>20$ & 85 & 25.4 & 280 & 31.9 \\
\hline \multicolumn{5}{|l|}{ Age at $1^{\text {st }}$ sex } \\
\hline$\leq 16$ & 256 & 45.6 & 401 & 42.5 \\
\hline$>16$ & 206 & 54.4 & 542 & 57.5 \\
\hline \multicolumn{5}{|l|}{ Duration of sexual activity* } \\
\hline$<5$ years & 372 & 66.4 & 145 & 15.4 \\
\hline$\geq 5$ years & 188 & 33.6 & 798 & 84.6 \\
\hline \multicolumn{5}{|l|}{ Contraceptive use ${ }^{* *}$} \\
\hline None & 373 & 65.3 & 567 & 59.1 \\
\hline Modern plus condom & 105 & 18.4 & 240 & 25.0 \\
\hline Other & 93 & 16.3 & 152 & 15.9 \\
\hline \multicolumn{5}{|l|}{ Previous births } \\
\hline $\mathrm{n} \leq 4$ & N/A & & 823 & 85.7 \\
\hline$n>4$ & & & 137 & 14.3 \\
\hline \multicolumn{5}{|l|}{ Previous Miscarriage } \\
\hline Yes & 41 & 7.2 & 76 & 7.9 \\
\hline No & 530 & 92.8 & 884 & 92.1 \\
\hline \multicolumn{5}{|l|}{ HIV status } \\
\hline Positive & 29 & 5.1 & 56 & 5.8 \\
\hline Negative & 543 & 95.0 & 904 & 94.2 \\
\hline \multicolumn{5}{|l|}{ Clinic } \\
\hline $\mathrm{A}$ & 248 & 43.4 & 451 & 47.0 \\
\hline $\mathrm{B}$ & 145 & 25.4 & 231 & 24.1 \\
\hline $\mathrm{C}$ & 63 & 11.0 & 94 & 9.8 \\
\hline $\mathrm{D}$ & 41 & 7.2 & 48 & 5.0 \\
\hline $\mathrm{E}$ & 50 & 8.8 & 68 & 7.1 \\
\hline $\mathrm{F}$ & 24 & 4.2 & 68 & 7.1 \\
\hline
\end{tabular}

* Other employment includes housewives with some part time, seasonal and self-workers, retired or disabled

** Sample might be lower because of missing records 
Table 2

Factors associated with previous induced abortion: Nulliparous women

\begin{tabular}{|c|c|c|c|c|}
\hline Characteristic & $\mathrm{n} / \mathrm{N}$ & $\%$ & $\begin{array}{l}\text { Crude OR } \\
(95 \% \text { CI })\end{array}$ & $\begin{array}{l}\text { Adjusted OR* } \\
(95 \% \mathrm{CI})\end{array}$ \\
\hline Previous induced abortion & $96 / 571$ & 16.8 & - & - \\
\hline \multicolumn{5}{|l|}{ All nulliparous women } \\
\hline \multicolumn{5}{|l|}{ Age group } \\
\hline$<20$ & $24 / 256$ & 9.4 & 1.0 & - \\
\hline $20-24$ & $38 / 224$ & 17.0 & $2.0(1.1-3.4)$ & $1.0 * *$ \\
\hline $25-29$ & $27 / 72$ & 37.5 & $5.8(2.9-11.4)$ & $2.9(1.6-5.4)$ \\
\hline$\geq 30$ & $7 / 18$ & 38.9 & $6.2(2.1-17.9)$ & - \\
\hline \multicolumn{5}{|l|}{ Education } \\
\hline Never/primary & $14 / 142$ & 9.9 & 1.0 & 1.0 \\
\hline Secondary & $62 / 376$ & 16.5 & $1.8(0.9-3.3)$ & $0.99(0.5-2.1)$ \\
\hline Higher & $20 / 53$ & 37.7 & $5.5(2.5-12.1)$ & $1.5(0.6-4.1)$ \\
\hline \multicolumn{5}{|c|}{ Current employment of woman } \\
\hline Full time & $13 / 64$ & 20.3 & $1.7(0.8-3.6)$ & $1.2(0.5-2.6)$ \\
\hline Housewife & $29 / 228$ & 12.7 & 1.0 & 1.0 \\
\hline Student & $32 / 147$ & 21.8 & $1.9(1.1-3.3)$ & $1.3(0.7-2.6)$ \\
\hline Other & $22 / 132$ & 16.7 & $1.3(1.1-3.3)$ & $1.4(0.7-2.9)$ \\
\hline \multicolumn{5}{|l|}{ Religion } \\
\hline Protestant & $31 / 158$ & 19.6 & 1.0 & 1.0 \\
\hline Catholic & $62 / 357$ & 17.4 & $0.9(0.5-1.4)$ & $0.8(0.5-1.4)$ \\
\hline Muslim/ Other & $3 / 56$ & 5.4 & $0.2(0.1-0.8)$ & $0.4(0.1-1.6)$ \\
\hline \multicolumn{5}{|l|}{ Ethnic group } \\
\hline Beti/Fan & $26 / 172$ & 15.1 & 1.0 & N/A \\
\hline Bamileke & $30 / 196$ & 15.3 & $1.0(0.6-1.8)$ & \\
\hline Other & $40 / 203$ & 19.7 & $1.4(0.8-2.4)$ & \\
\hline \multicolumn{5}{|l|}{ Time spent in city } \\
\hline$<2$ years & $12 / 158$ & 7.6 & 1.0 & 1.0 \\
\hline$\geq 2$ years & $84 / 413$ & 20.3 & $3.1(1.6-5.9)$ & $2.2(1.1-4.4)$ \\
\hline \multicolumn{5}{|l|}{ Marital status } \\
\hline Never married & $34 / 222$ & 15.3 & $0.9(0.5-1.4)$ & N/A \\
\hline Married & $54 / 320$ & 16.9 & 1.0 & \\
\hline Past married & $8 / 29$ & 27.6 & $1.9(0.8-4.4)$ & \\
\hline \multicolumn{5}{|l|}{ Contraceptive use } \\
\hline None & $51 / 373$ & 13.7 & 1.0 & 1.0 \\
\hline Modern plus condom & $29 / 105$ & 27.6 & $2.4(1.4-4.0)$ & $1.8(1.0-3.2)$ \\
\hline Other & $16 / 93$ & 17. & $1.3(0.7-2.4)$ & $1.2(0.6-2.4)$ \\
\hline \multicolumn{5}{|l|}{ Age at first marriage } \\
\hline$<17$ & $7 / 75$ & 9.3 & 1.0 & \\
\hline $17-20$ & $30 / 174$ & 17.2 & $.0(0.8-4.8)$ & N/A \\
\hline$>20$ & $20 / 85$ & 23.3 & $3.0(1.2-7.5)$ & \\
\hline \multicolumn{5}{|l|}{ Age at first sex } \\
\hline$\leq 16$ & $34 / 256$ & 13.3 & 1.0 & 1.0 \\
\hline$>16$ & $61 / 305$ & 20.0 & $1.6(1.03-2.6)$ & $0.9(0.5-1.4)$ \\
\hline \multicolumn{5}{|l|}{ Duration of sexual activity } \\
\hline$<5$ years & $40 / 372$ & 10.7 & 1.0 & N/A \\
\hline$\geq 5$ years & $55 / 188$ & 29.3 & $3.4(2.2-5.4)$ & \\
\hline \multicolumn{5}{|l|}{ Previous Miscarriage } \\
\hline No & $87 / 530$ & 16.42 & 1.0 & N/A \\
\hline Yes & $9 / 41$ & 21.95 & $1.4(0.7-3.1)$ & \\
\hline \multicolumn{5}{|l|}{ HIV Status } \\
\hline Positive & $7 / 29$ & 24.1 & 1.0 & N/A \\
\hline Negative & $89 / 542$ & 16.4 & $0.6(0.2-1.5)$ & \\
\hline \multicolumn{5}{|l|}{ Clinic } \\
\hline $\mathrm{A}$ & $55 / 248$ & 22.2 & 1.0 & 1.0 \\
\hline $\mathrm{B}$ & $18 / 145$ & 12.4 & $0.5(0.3-0.9)$ & $0.5(0.3-1.0)$ \\
\hline $\mathrm{C}$ & $10 / 63$ & 15.9 & $0.7(0.3-1.4)$ & $0.7(0.3-1.7)$ \\
\hline $\mathrm{D}$ & $5 / 41$ & 12.2 & $0.5(0.2-1.3)$ & $0.6(0.2-1.7)$ \\
\hline $\mathrm{E}$ & $7 / 50$ & 14.0 & $0.6(0.2-1.3)$ & $0.6(10.2-1.5)$ \\
\hline $\mathrm{F}$ & $1 / 24$ & 4.2 & $0.1(0.02-1.1)$ & $0.3(0.03-2.2)$ \\
\hline
\end{tabular}

* After logistic regression including the variables above, except those mentioned as Non Applicable (NA); OR in bold if p value $\leq 0.05$. **Reference category is age $<25$ (vs age $\geq 25$ ) 
Table 3

Factors associated with previous induced abortion: Multiparous women

\begin{tabular}{|c|c|c|c|c|}
\hline Characteristic & $\mathrm{n} / \mathrm{N}$ & $\%$ & $\begin{array}{l}\text { Crude OR } \\
(95 \% \text { CI })\end{array}$ & $\begin{array}{l}\text { Adjusted OR* } \\
(95 \% \mathrm{CI})\end{array}$ \\
\hline Previous induced abortion & $208 / 960$ & 21.7 & - & - \\
\hline \multicolumn{5}{|l|}{ All multiparous women } \\
\hline \multicolumn{5}{|l|}{ Age group } \\
\hline$<20$ & $9 / 53$ & 17.0 & 1.0 & - \\
\hline $20-24$ & $48 / 305$ & 15.7 & $0.9(0.4-1.9)$ & - \\
\hline $25-29$ & $59 / 340$ & 17.4 & $1.03(0.5-2.2)$ & $1.0 * *$ \\
\hline$\geq 30$ & $92 / 262$ & 35.1 & $2.7(1.2-5.7)$ & $2.4(1.6-3.5)$ \\
\hline \multicolumn{5}{|l|}{ Education } \\
\hline Never/primary & $56 / 334$ & 16.8 & 1.0 & $1.0^{* * *}$ \\
\hline Secondary & $134 / 566$ & 23.7 & $1.5(1.1-2.2)$ & $1.3(0.9-1.9)$ \\
\hline Higher & $18 / 60$ & 30.0 & $2.1(1.1-4.0)$ & - \\
\hline \multicolumn{5}{|c|}{ Current employment of woman } \\
\hline Full time & $33 / 97$ & 34.0 & $2.1(1.3-3.4)$ & $1.8(1.0-3.0)$ \\
\hline Housewife & $112 / 575$ & 19.5 & 1.0 & 1.0 \\
\hline Student & $9 / 63$ & 14.3 & $0.7(0.3-1.4)$ & $0.7(0.3-1.6)$ \\
\hline Other & $54 / 225$ & 24.0 & $1.3(0.9-1.9)$ & $1.2(0.8-1.9)$ \\
\hline \multicolumn{5}{|l|}{ Religion } \\
\hline Protestant & $238 / 238$ & 22.7 & 1.0 & \\
\hline Catholic & $137 / 601$ & 22.8 & $1.0(0.7-1.4)$ & N/A \\
\hline Muslim Other & $17 / 121$ & 14.5 & $0.6(0.3-1.0)$ & \\
\hline \multicolumn{5}{|l|}{ Ethnic group } \\
\hline Beti/Fan & $84 / 303$ & 27.7 & $1.8(1.1-2.6)$ & $1.4(0.9-2.2)$ \\
\hline Bamileke & $74 / 373$ & 19.8 & $1.2(0.8-1.7)$ & $1.0(0.7-1.6)$ \\
\hline Other & $54 / 284$ & 17.6 & 1.0 & 1.0 \\
\hline \multicolumn{5}{|l|}{ Time spent in city } \\
\hline$<2$ years & $19 / 96$ & 19.8 & 1.0 & N/A \\
\hline$\geq 2$ years & $189 / 864$ & 21.9 & $1.1(0.7-1.9)$ & \\
\hline \multicolumn{5}{|l|}{ Marital status } \\
\hline Never married & $18 / 65$ & 27.7 & $1.5(0.8-2.6)$ & N/A \\
\hline Married & $176 / 850$ & 20.7 & 1.0 & \\
\hline Past married & $14 / 45$ & 31.1 & $1.7(0.9-3.2)$ & \\
\hline \multicolumn{5}{|l|}{ Contraceptive use } \\
\hline None & $107 / 567$ & 18.9 & 1.0 & 1.0 \\
\hline Modern plus condom & $57 / 240$ & 23.8 & $1.4(0.9-1.9)$ & $1.1(0.8-1.6)$ \\
\hline Other & $44 / 152$ & 29.0 & $1.7(1.2-2.6)$ & $1.5(0.95-2.3)$ \\
\hline \multicolumn{5}{|l|}{ Age at first marriage } \\
\hline$<17-20$ & $31 / 166$ & 18.7 & 1.0 & \\
\hline $17-20$ & $79 / 431$ & 18.3 & $0.9(0.6-1.5)$ & N/A \\
\hline$>20$ & $77 / 280$ & 27.5 & $1.6(1.0-2.6)$ & \\
\hline \multicolumn{5}{|l|}{ Age at first sex } \\
\hline$\leq 16$ & $89 / 401$ & 22.2 & 1.0 & N/A \\
\hline$>16$ & $114 / 542$ & 21.0 & $0.9(0.7-1.3)$ & \\
\hline \multicolumn{5}{|l|}{ Duration of sexual activity } \\
\hline$<5$ years & $20 / 145$ & 13.8 & 1.0 & N/A \\
\hline$\geq 5$ years & $183 / 798$ & 22.9 & $1.9(1.1-3.1)$ & \\
\hline \multicolumn{5}{|l|}{ Previous birth } \\
\hline$\leq 4$ & $166 / 823$ & 20.2 & 1.0 & 1.0 \\
\hline$\overline{>4}$ & $42 / 137$ & 30.7 & $1.7(1.2-2.6)$ & $1.1(0.7-1.8)$ \\
\hline \multicolumn{5}{|l|}{ Previous Miscarriage } \\
\hline No & $197 / 884$ & 22.3 & 1.0 & N/A \\
\hline Yes & $11 / 76$ & 14.47 & $0.6(0.3-1.2)$ & \\
\hline \multicolumn{5}{|l|}{ HIV Status } \\
\hline Positive & $12 / 56$ & 21.4 & 1.0 & N/A \\
\hline Negative & $196 / 904$ & 21.7 & $1.0(0.5-1.9)$ & \\
\hline \multicolumn{5}{|l|}{ Clinic } \\
\hline $\mathrm{A}$ & $120 / 451$ & 26.6 & 1.0 & 1.0 \\
\hline $\mathrm{B}$ & $47 / 231$ & 20.3 & $10.7(0.5-1.0)$ & $0.6(0.4-0.98)$ \\
\hline $\mathrm{C}$ & $7 / 94$ & 7.4 & $0.2(0.1-0.5)$ & $0.3(0.1-0.7)$ \\
\hline $\mathrm{D}$ & $7 / 48$ & 14.6 & $0.5(0.2-1.1)$ & $0.5(0.2-1.1)$ \\
\hline $\mathrm{E}$ & $20 / 68$ & 29.4 & $1.1(0.6-2.0)$ & $1.1(0.6-2.1)$ \\
\hline $\mathrm{F}$ & $7 / 68$ & 10.3 & $0.3(0.1-0.7)$ & $0.4(0.2-0.9)$ \\
\hline
\end{tabular}

* After logistic regression including the variables above except those mentioned as Non Applicable (NA). ${ }^{* *}$ Reference category is age $<30$ (vs age $\geq 30$ ). ${ }^{* * *}$ Reference category is never/primary education (vs secondary and higher) 


\section{Figure 1}

Distribution of induced abortion by age group and parity

Induced abortion and factors associated with previous abortion.

Multiparous women: Of the multiparous women $22 \%$ reported a history of induced abortion between the last birth and the current pregnancy (Table 3). Seven percent of women reported two or more abortions (range: 1 to 8 abortions). In univariate analysis women with a higher educational level and women with a full time employment were more likely to report a history of abortion. Beti and Fan women more often reported abortion than women of other ethnic groups. The use of other than modern contraceptive methods, later age at first marriage, longer time since sexual debut and higher number of previous births were all positively associated with a report of abortion. In general, women who attended ANCs other than Clinic A were less likely to report abortion. In multivariate analysis, age 30 years or older and having a full time employment were statistically significantly associated with a history of abortion. Attendance at Clinics B, C, and F was associated with a reduced likelihood of a history of induced abortion.

\section{DISCUSSION}

In this study a considerable proportion of women attending antenatal clinics in Yaounde, Cameroon, reported a history of one or more induced abortions. Of the nulliparous women that were interviewed $17 \%$ reported that they ever had one or more abortions. Of the multiparous women $22 \%$ reported that they had one or more induced abortions between the last birth and the current pregnancy. Both groups of women reported similar rates of miscarriage $(7.9 \%$ for multiparous women and $7.2 \%$ for nulliparous women) which suggests that induced abortion might be more common among multiparous women. Another possibility is that some multiparous women did not make the distinction between 'ever had abortion' and 'abortion since last birth'. Four multiparous women reported five to eight induced abortions, which is an unlikely figure for the interval between last birth and current pregnancy. The possibility that nulliparous women might under report abortion more than multiparous women also cannot be excluded.

Data on the practice of induced abortion in the general population are scarce because women may be reluctant to report it, especially in acute situations. In a community based study in Nigeria, $21.2 \%$ of adolescents aged 17-19 reported an induced abortion (18). Previous studies on induced abortion among adolescents in Cameroon found rates of reported abortion from $9 \%$ to $20 \%(12,13)$, similar to our results. In a study in Abidjan, Cote d'Ivoire, $25.3 \%$ of all ANC women reported at least one induced abortion (19). In Kisumu (Kenya) and in Ndola (Zambia), a similar study (with the same questionnaire) among ANC attendees was conducted. In these two cities, fewer women reported one or more previous abortions: the proportions who reported abortion ranged between $3 \%$ and $9 \%$ (16). It is not clear whether induced abortion is more common in Yaounde than in the other two cities or whether women in Yaounde feel more free to talk about abortion than women in Kisumu and Ndola.

The figures on abortion which we found among women attending ANC cannot be extrapolated to the general population. The women in our study seemed to have an educational attainment level that was considerably higher than that in the general population of Yaounde (16). As induced abortion was associated with higher education level, though only marginally in the multivariate analysis, the rates found in our study are likely overestimates compared to what happens in the general population. On the other hand, women seen in the ANC are those who are planning to continue with the current pregnancy: they are likely to have higher fertility than the general population but may also be those who are less likely to choose abortion.

The factors we found to be associated with abortion in our study are similar to the ones reported in the literature (20-22). Older nulliparous and multiparous women were more likely to report a history of abortion. In nulliparous women the use of modern contraception was associated with a higher likelihood of induced abortion. The questions about the use of contraceptive methods did not specify when contraception was used, i.e. before or after abortion. So, it is possible that nulliparous women started using a modern contraceptive method after they had had an abortion. In multiparous women history of abortion was associated with the use of a traditional method of contraception. However this association was not statistically significant in multivariate analysis. The low contraceptive prevalences found in our study were comparable to those found in previous studies in Cameroon. Despite a high level of awareness of modern contraceptive methods, $80 \%$ in women and $88 \%$ in men, the contraceptive prevalence for all women in 1998 was $24 \%$ with only $8 \%$ using a modern method, 
essentially condoms (23). There are plans developed by the Cameroonian government to promote family planning and sex education with a progressive increase in the acceptability of modern contraceptive methods but programmes have not yet reached the majority of the people $(23,24)$. It is likely that abortion is used as a method of fertility control, especially among multiparous women. Among nulliparous women, the time spent in the city (two years or more) was associated with an increased likelihood of induced abortion. Nulliparous women are likely to have come to the city to study, to get married or to look for a job. Spending time in the city might change their way of living and increase their risk behaviour. Longer time in the city may also indicate that they are more knowledgeable about where to get an abortion.

Both nulliparous women and multiparous women were less likely to report abortion when they attended certain clinics. These clinics were affiliated with religious groups. It is unclear whether women attending these clinics have less abortions or whether they are more reluctant to admit to it as the ANC setting may have discouraged accurate disclosure of abortion histories.

In conclusion, this study shows that, in spite of restrictive laws and religious proscriptions, induced abortion is occurring frequently in this urban population in Cameroon. In this context unsafe abortions are likely to be frequent with the risk of associated complications. In order to improve sexual and reproductive health, emphasis should therefore be put on prevention and expanded sexual and reproductive health programmes, including facilities for sex education, contraception and STI prevention and care.

\section{ACKNOWLEDGEMENTS}

We are grateful to the research assistants for their time spent during the period of data collection and to the women who shared their time and experience. The study on ANC HIV surveillance, on which this work was based, was funded by UNAIDS.

\section{REFERENCES}

1. World Health Organisation (WHO) Division of reproductive health. Unsafe abortion: Global and regional estimates of incidence and mortality due to unsafe abortion with a listing

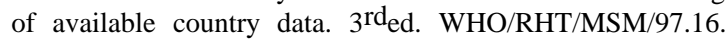
WHO, Geneva; 1998.

2. African Population Newsletter [APN].Legislation on abortion 1995; 67:5-6.

3. Germain, A., and Kim, T. Expanding access to safe abortion: strategies for action. International Women's Health Coalition, New York; 1998.

4. Lantum, D. N. Some characteristics of women dying from abortion in Cameroon. Paper presented at the IPPF conference on the medical and social aspects of abortion in Africa, Accra, Ghana, December, 1973; 13-18.

5. Nasah, B. T. Aetiology of infertility in Cameroon. Nig. Med. J. 1979; 9:601-605.

6. Megafu, U. and Ozumba, B. C. Morbidity and mortality from induced illegal abortion at the University of Nigeria teaching Hospital, Enugu: a five year review. Inter. J. Gynec. Obstet. 1991; 34:163-167.
7. Adewole, I. F. Trends in postabortal mortality and morbidity in Ibadan, Nigeria. Inter. J. Gynae. Obstet. 1992; 38:115-118.

8. Mbanya, D. Blood transfusion in obstetrics and gynaecology services, Yaounde, Cameroon: a health hazard for women? In: The health of women and safe motherhood. Presentations at the first regional congress of the Medical Women's International Association, Near East and African Region Nov 29-Dec 3 1993, Nairobi, Kenya: Kenya Medical Women's Association; p. 61.

9. Leke, R. J., Oduma, J. A., Bassol-Mayagoitia, S., et al. Regional and geographical variation in infertility: effects of environmental, cultural and socioeconomic factors. Environmental Health Perspective. 1993; 101(Supl 2):73-80.

10. Tumasang, F. N. Ectopic pregnancy: a review of trends and management at 'Maternite Principale' in Yaounde, Cameroon. In: The health of women and safe motherhood. Presentations at the first regional congress of the Medical Women's International Association, Near East and African Region Nov 29-Dec 3 1993, Nairobi, Kenya: Kenya Medical Women's Association; p. 5256.

11. Nasah, B.T., Otubu, J. A. Infertility. In: Nasah, B.T., Mati, K.G., Kasonde, J.M. (editors): Contemporary issues in maternal health care in Africa. Harwood Academic Publishers; 1994; 337-369.

12. Meekers, D. and Calves, A. E. Gender differentials in adolescents' sexual activity and reproductive health risks in Cameroon. Population Services International Research Division (Working paper No. 4), Washington DC; 1997.

13. Centre for African Family Studies [CAFS]. Determinants and consequences of adolescent pregnancies in Cameroon. CAFS News 1996; 6: 8.

14. Ilinigumugabo, A., Walla, G. and Azambo, M. Centre d'Etudes de la Famille Africaine 4. Research report series. 1996; No. 3.

15. Kamtchouing, P., Takougang, I., Ngoh, N. and Yakam, I. Sexuality of adolescents student in Yaounde (Cameroon). Contra. Fert. Sexualite. 1997; 25: 798-801.

16. Glynn, J. R., Buve, A., Carael, M., Musonda, K. et al. Factors influencing the difference in HIV prevalence between antenatal clinic and general population in sub-Saharan Africa. AIDS . 2001; 15: 1717-1725.

17. Glynn, J. R., Buve, A,, Carael, M., et al. Decreased fertility among HIV-l-infected women attending antenatal clinics in three African cities. J. Acqui. Immu. Def. Syndromes. 2000; 25:345-352.

18. Brabin, L., Kemp, J., Obunge, O. K. et al. Reproductive tract infections and abortion among adolescent girls in rural Nigeria. Lancet. 1995; 345:300-304.

19. Desgrees, du Lou, A., Msellati, P., Viho, I., Welfens-Ekra, C. Le recours a' l'avortement provoque a Abidjan. Une cause de baisse de la fecondite? Population. 1999; 54:427-446

20. Aggarwal, V. P., and Mati, J. K. Review of abortions at Kenyatta National Hospital, Nairobi. East Afr. Med. J. 1980; 57:138-143.

21. Lin, I., Shi-zhong, W., Xiao-qing, C., and Min-xiang, L. Induced abortion among unmarried women in Sichuan Province, China: A survey. In: Mundigo AI, Idriso, C. (editors). Abortion in the developing world. Zeb Books, London; 1999; 337-345.

22. Tai-hwan, K., Hee, K. J. and Sung-nam, C. Sexuality, contraception and abortion among unmarried adolescents and young adults: The case of Korea. In: Mundigo AI, Indriso $\mathrm{C}$ (editors). Abortion in the developing world. Zeb Books, London; 1999; 346-367.

23 Fotso, M., Ndonou, R., Libite, P. R. et al. Enquete Demographique et de Sante, Cameroun 1998. Bureau central des recensements et des etudes de Population et al. Macro International Inc, Calverton, USA; 1999.

24. Gubry, P. Cameroon: from a moderate pronatalist policy to a moderate anti-natalist policy? In: Gubry P, Diakanda MS (editors). Politique Africaine en matiere de fecondite: de nouvelles tendances. Paris, France: Centre Francais sur la Population et le developpement (CEPED); 1988; 23-48. 